\title{
MENGEMBANGKAN LIVELIHOOD SKILLS SISWA SMK MELALUI PELATIHAN SAPONIFY HANDMADE SOAP ENTREPRENEURIAL DI KOTA SERANG
}

\author{
Rina Oktaviyanthi ${ }^{*}$, Nugraheni Djamal, Ria Noviana Agus \\ Universitas Serang Raya, Serang, Banten \\ *rinaokta1210@yahoo.com
}

\begin{abstract}
Abstrak
Keilmuan mengenai livelihood skills dan entrepreneurial skills perlu ditanamkan sejak dini pada kaum muda. Hal tersebut dilakukan untuk memberdayakan potensi ekonomi serta membangun masyarakat mandiri yang akan memunculkan sebanyak-banyaknya individu kreatif yang dapat melihat peluang membuka usaha/ lapangan kerja baru. Ada banyak metode untuk melatihkan livelihood skills (keahlian mencari penghidupan) dan entrepreneurial skills (keahlian wirausaha), salah satunya adalah dengan pelatihan di bidang Saponify Handmade Soap. Pengabdian ini memokuskan pada pengembangan livelihood skills dan entrepreneurial skills siswa SMK melalui pelatihan di bidang Saponify Handmade Soap. Alasan dipilihnya SMK sebagai mitra kegiatan pengabdian ini karena keberadaan SMK dalam mempersiapkan individu yang produktif, terampil, dan mandiri perlu semakin ditingkatkan. Adapun metode yang digunakan adalah pelatihan di bidang Saponify Handmade Soap, harapannya (1) agar siswa SMK memiliki pengetahuan dan pengalaman dalam pembuatan produk di luar keahlian yang diajarkan di sekolah, (2) agar siswa SMK dapat membuat produk kebersihan rumah tangga skala rumahan baik untuk digunakan sendiri maupun sebagai sarana wirausaha, dan (3) agar keahlian siswa dalam hal livelihood (penghidupan/ mencari nafkah) dan entrepreneurial terasah dan lebih jauhnya dapat membuka lapangan usaha/ kerja baru.
\end{abstract}

Kata Kunci: entrepreneurial skills, livelihood skills, sabun rumah tangga, saponify handmade, smk

\section{PENDAHULUAN}

Sekolah Menengah Kejuruan (SMK) merupakan salah satu pendidikan formal pada jenjang pendidikan menengah di Indonesia yang memiliki pola penyelenggaraan kegiatan belajar khusus. Penyelenggaraan kegiatan khusus tersebut bertujuan mempersiapkan peserta didiknya dengan pengetahuan, 
keterampilan dan keahlian tertentu sehingga menjadi lulusan yang siap terjun di lapangan secara professional sesuai kompetensi dan program keahliannya, memiliki daya adaptasi dan daya saing mumpuni serta turut bergerak di dunia kerja atau usaha. Hal itu ditegaskan dalam Undang-Undang Nomor 20 Tahun 2003 tentang Sistem Pendidikan Nasional pasal 15 bahwa pendidikan kejuruan merupakan pendidikan menengah yang mempersiapkan peserta didik untuk bekerja dalam bidang tertentu [1]. Tujuan khusus pendidikan menengah kejuruan salah satunya adalah menyiapkan peserta didik agar menjadi manusia produktif, mampu bekerja mandiri, mengisi lowongan pekerjaan sebagai tenaga kerja tingkat menengah sesuai dengan kompetensi [2].

Keberadaan SMK dalam mempersiapkan individu yang produktif, terampil dan mandiri masih perlu ditingkatkan. Hal tersebut perlu dilakukan sebab SMK menjadi alternatif pengembangan pendidikan menengah untuk mengatasi masalah pengangguran [3]. Namun yang sangat bertolak belakang adalah data di lapangan menunjukkan adanya peningkatan persentase angka pengangguran lulusan sekolah kejuruan. Berdasarkan data dari Badan Pusat Statistik (BPS) persentase pengangguran untuk lulusan SMK pada Februari 2012 sampai Februari 2013 mengalami peningkatan dari $10.54 \%$ menjadi $11.79 \%$ [4]. Begitu pula pada Agustus 2012 sampai Agustus 2013, persentase pengangguran lulusan SMK dari $11.84 \%$ menjadi $12.74 \%$ [5]. Belum semua lulusan SMK dapat memenuhi kualifikasi lapangan kerja sesuai keahlian. Faktornya adalah adanya kesenjangan antara keterampilan yang dimiliki oleh lulusan SMK dengan keterampilan yang dibutuhkan di dunia kerja. Seperti yang ditegaskan oleh Badan Kajian Ekonomi Regional Provinsi Banten Triwulan II tahun 2013, bahwa faktor penyebab angka pengangguran di wilayah Provinsi Banten adalah faktor ketersediaan tenaga kerja yang tidak sesuai dengan kebutuhan [6]. Untuk menanggulangi hal tersebut, salah 
satunya adalah menyesuaikan kurikulum dengan keahlian yang dibutuhkan di lapangan. Namun hal tersebut tentu tidak mudah, perlu pengkajian yang mendalam dan seringkali pengambilan keputusan untuk suatu kebijakan membutuhkan waktu yang tidak singkat, sementara angka persentase pengangguran lulusan SMK semakin bertambah. Lalu apa yang dapat dilakukan?

Mengembangkan livelihood skills pada peserta didik dapat menjadi alternatif dalam mengurangi pengangguran. Seperti yang diungkapkan oleh para ahli DFID, bahwa:

The concept of livelihoods has gained wide acceptance as a valuable means of understanding the factors that influence people's lives and wellbeing, particularly those of the poor in the developing world for reducing unemployment [7].

Livelihood skills atau keterampilan mencari nafkah/ penghidupan mengacu pada kemampuan, sumber daya dan peluang untuk mengejar tujuan individu dan ekonomi rumah tangga dan berhubungan dengan peningkatan pendapatan. Salah satu aspek livelihood skills seperti yang dijelaskan oleh Tim International Recovery Platform (IRP) adalah employment opportunities (kesempatan kerja) [11]. Keterampilan mencari nafkah sebagai bekal untuk mencari kesempatan bekerja dapat dikembangkan melalui keahlian kewirausahaan. Hal tersebut diungkapkan EQUIP3 bahwa:

The objectives of livelihood and trade skills are achieved through the following areas of learning: basic technical drawing, designing skills, food and nutrition, agriculture, woodwork, metalwork, fashion and fabrics, housekeeping, bicycle and motorcycle maintenance, workshop practices, entrepreneurial skills, new technological practices, and basic electricity [12].

Pengembangan pendidikan kewirausahaan sudah menjadi program pemerintah dan diprogramkan secara formal untuk periode tahun 2010-2014 melalui PEK (Pengembangan Ekonomi Kreatif). Salah satu poin kebijakan PEK 
adalah pengajaran kewirausahaan yang tidak hanya mengajarkan teori semata, tetapi lebih menitikberatkan pada praktek secara langsung [8]. Kebijakan PEK tersebut didukung oleh Kementrian Perencanaan yang mengidentifikasi lima strategi untuk meningkatkan penciptaan lapangan kerja bagi kaum muda, salah satunya yaitu peningkatan kesempatan untuk kewirausahaan kaum muda [9].

SMKN 5 yang terletak di Kecamatan Curug, SMK YP 17 dan SMK Al Had Nusantara di Kecamatan Taktakan merupakan tiga diantara 32 SMK (5 SMK negeri dan 27 SMK swasta) yang terdapat di Kabupaten Kota Serang dan diketahui belum mengoptimalkan aspek kewirausahaan untuk mengembangkan livelihood skills peserta didiknya terutama dalam bidang Saponify Handmade Soap. Melalui Tanya jawab singkat dengan masing-masing kepala sekolah, diperoleh keterangan bahwa keahlian yang dipelajari dan didalami hanya keahlian sesuai jurusan yang ada pada masing-masing sekolah. SMKN 5 memokuskan pada teknik sepeda motor, teknik komputer dan jaringan, administrasi perkantoran dan akuntansi. Sementara SMK YP 17 menitikberatkan pada teknik pemeliharaan mekanik industri, teknik mekanik otomotif, dan teknik pemanfaatan tenaga listri. Sedangkan SMK Al Had Nusantara memusatkan keahlian pada tata busana, otomotif sepeda motor, administrasi perkantoran, akomodasi perhotelan dan teknik kendaraan ringan. Penulis mendapat informasi lanjutan dari sampel acak 5 orang siswa pada masing-masing sekolah melalui penyebaran angket sederhana tentang (1) apakah ada keahlian lain yang dilatihkan di luar keahlian yang sudah ada di sekolah dan (2) perlukah diadakan pelatihan lain yang terkait dengan livelihood skills (keahlian mencari penghidupan) dan entrepreneur skills (keahlian wirausaha). Dari 15 orang siswa semuanya memberi tanda ceklis pada kolom 'tidak' untuk pertanyaan (1) dan memberi tanda ceklis pada kolom 'ya' untuk pertanyaan (2). Kesimpulan sementara dari penyebaran angket sederhana untuk 
menjaring data awal itu adalah bahwa di masing-masing sekolah mitra belum pernah dilakukan kegiatan pelatihan dalam upaya mengembangkan livelihood skills dan entrepreneur skills khususnya dalam bidang Saponify Handmade Soap.

Merujuk Rencana Strategi Direktorat Jenderal Pendidikan Menengah (Renstra Ditjen Dikmen) 2010-2014 mengenai dua diantara lima kebijakan pengembangan metodologi pendidikan kewirausahaan yaitu (1) peningkatan jumlah dan perbaikan kualitas lembaga pendidikan menengah yang mendukung penciptaan insan kreatif dalam pengembangan ekonomi kreatif, dan (2) mendorong akademisi/ wirausahawan untuk berbagi pengalaman dan keahlian di institusi pendidikan menengah dalam pengembangan ekonomi kreatif [10]. Maka dipandang perlu adanya knowledge sharing mengenai livelihood skills dan entrepreneurial skills melalui pelatihan pembuatan Saponify Handamde Soap. Adapun tujuan knowledge sharing ini diantaranya yaitu (1) sebagai wadah berbagi pengetahuan dan pengabdian pada masyarakat dalam hal ini siswa SMK, (2) untuk menggali potensi, pengetahuan, minat dan keahlian pada masing-masing siswa di luar kurikulum sekolah, dan (3) sebagai media untuk membangun jiwa entrepreneur yang dapat dikembangkan untuk membuka lapangan usaha/ kerja.

\section{METODE}

Titik berat kegiatan IbM ini adalah pada aspek livelihood skills dan entrepreneurial skills, dimana perlu adanya pengembangan kedua keahlian tersebut sebagai tambahan keahlian yang perlu dikuasai siswa di luar keahlian yang diajarkan di sekolah. Pengembangan aspek livelihood skills dan entrepreneurial skills ini selain untuk tambahan keahlian, diharapkan pula menjadi referensi dan inspirasi siswa dalam mengembangkan kemampuan, minat. 
bakat, dan keahlian sehingga dapat digunakan sebagai alternatif peluang membuka usaha/ kerja baru.

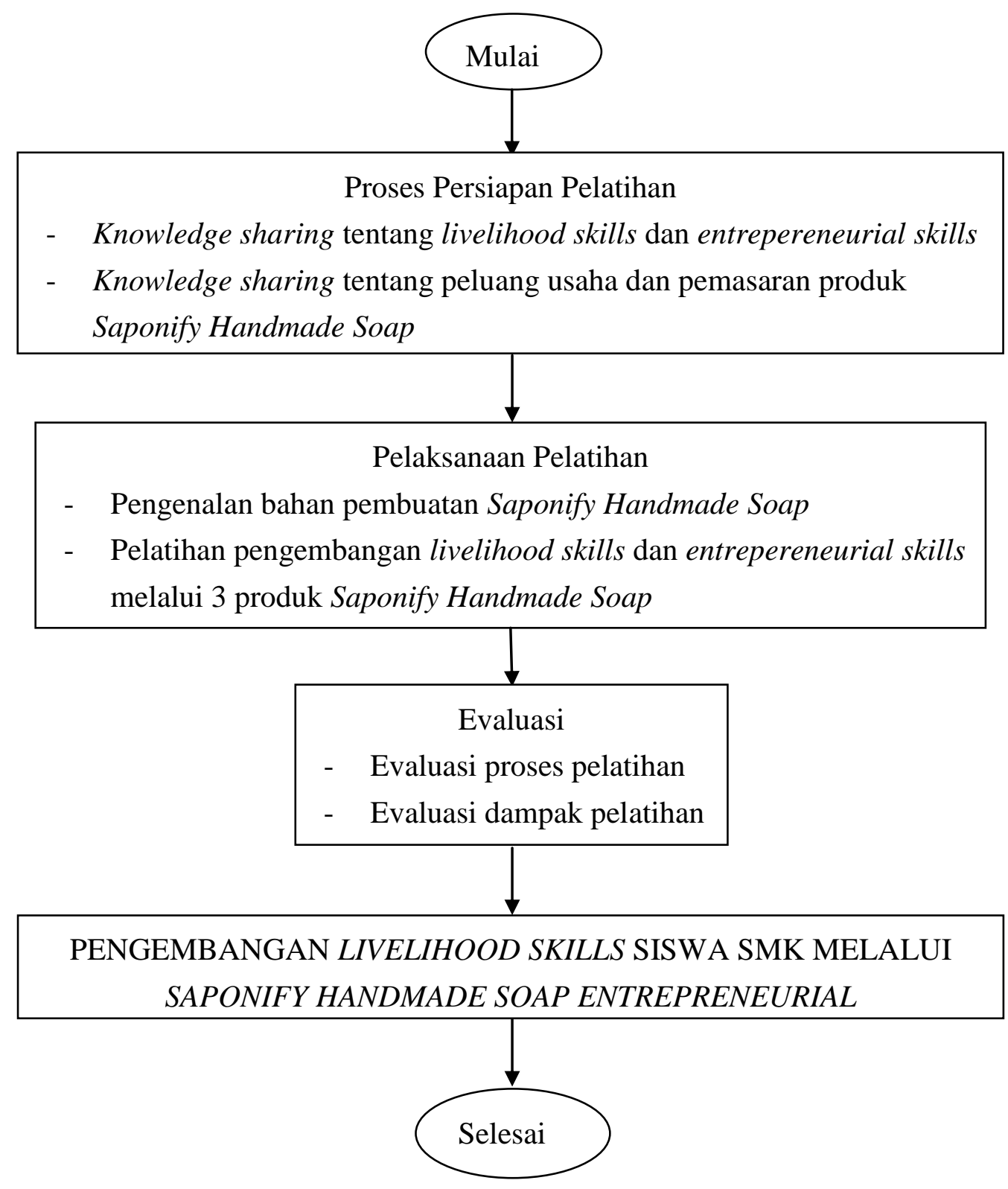

Gambar 1 Bagan Tahap-tahap Kegiatan Pelatihan Program IbM

Metode yang dipilih adalah pelatihan livelihood skills dan entrepreneur skills melalui pelatihan Saponify Handamade Soap dengan pengumpulan data menggunakan observasi dan angket. Saponify Handmade Soap adalah pembuatan produk kebersihan rumah tangga skala rumahan yang terdiri dari pembuatan liquid body wash, liquid dish soap dan liquid floor cleaner. Rasionalisasi pemilihan Saponify Handamade Soap sebagai materi pelatihan yaitu (1) agar siswa SMK 
memiliki pengetahuan dan pengalaman dalam pembuatan produk di luar keahlian yang diajarkan di sekolah, (2) agar siswa SMK dapat membuat produk kebersihan rumah tangga skala rumahan baik untuk digunakan sendiri maupun sebagai sarana wirausaha, dan (3) agar keahlian siswa dalam hal livelihood (penghidupan/ mencari nafkah) dan entrepreneurial terasah dan lebih jauhnya dapat membuka lapangan usaha/ kerja baru.

\section{HASIL DAN PEMBAHASAN}

Kegiatan pelatihan Saponify Handamade Soap ini terbagi ke dalam tiga tahap yaitu (1) proses persiapan pelatihan, terbagi menjadi dua kegiatan yaitu (a) knowledge sharing tentang livelihood skills dan entrepreneurial skills dan (b) knowledge sharing tentang peluang usaha dan pemasaran prosuk Saponify Handmade Soap; (2) pelaksanaan pelatihan yang terdiri atas (a) pengenalan bahan pembuatan Saponify Handmade Soap dan (b) pelatihan pembuatan Saponify Handmade Soap; dan (3) evaluasi.

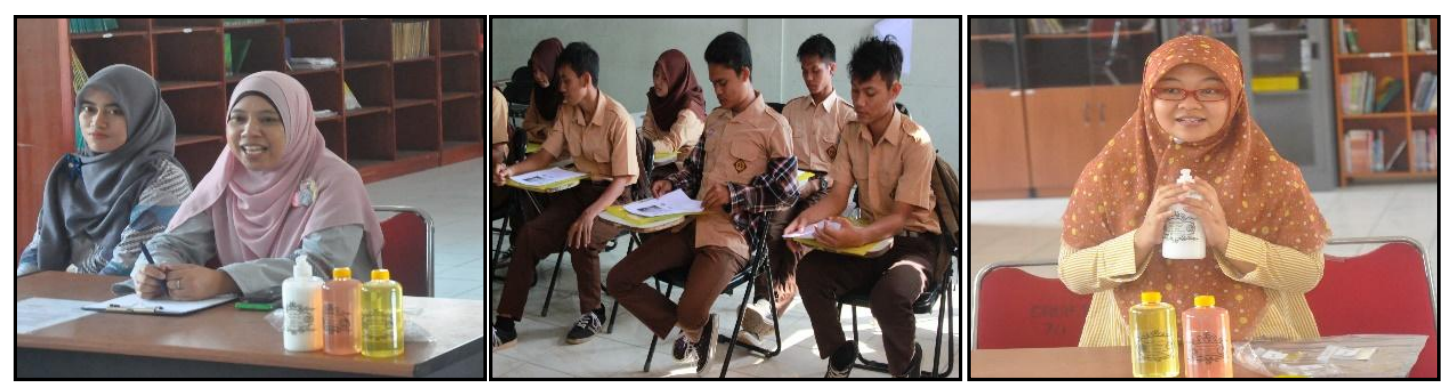

Gambar 2. Proses Persiapan Pelatihan
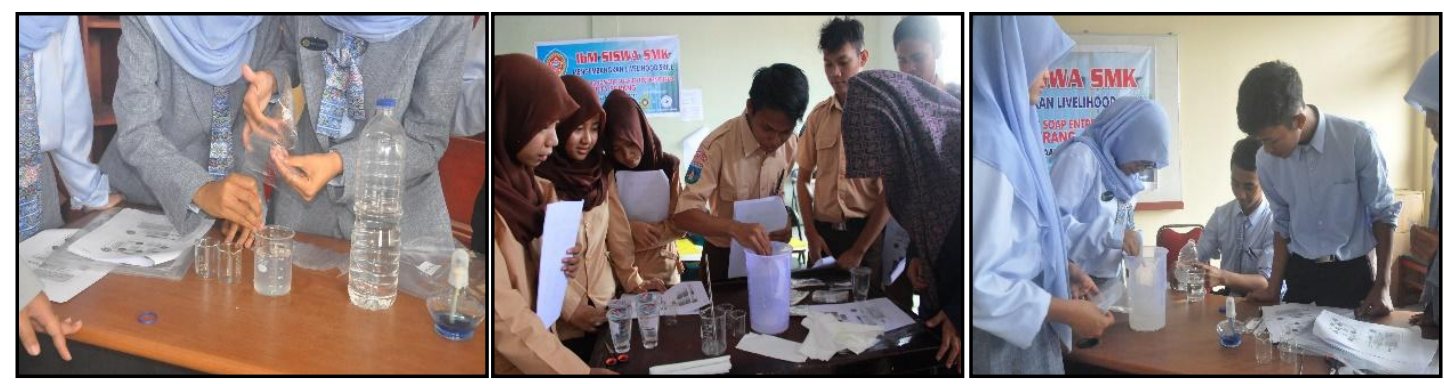

Gambar 3. Pelaksanaan Pelatihan 
Evaluasi dilakukan dengan pengambilan data melalui observasi dan pengisian angket. Tabel 1 menginformasikan persentase hasil obervasi mengenai pemahaman materi pelatihan. Ada tiga materi yang dilatihkan pada siswa yaitu (1) pelatihan 1, pembuatan produk sabun mandi cair (liquid body wash), (2) pelatihan 2, pembuatan produk sabun pencuci piring (liquid dish soap), dan (3) pelatihan 3 , pembuatan produk sabun pembersih lantai (liquid floor cleaner).

Tabel 1. Persentase Hasil Observasi Pemahaman Materi Pelatihan

\begin{tabular}{|c|c|c|c|c|}
\hline \multirow{2}{*}{ No } & \multirow{2}{*}{ Aspek yang diamati } & \multicolumn{3}{|c|}{ Persentase } \\
\hline & & Pelatihan 1 & Pelatihan 2 & Pelatihan 3 \\
\hline 1 & $\begin{array}{l}\text { Siswa menyatakan ulang alat dan bahan yang } \\
\text { digunakan sesuai pemahamannya }\end{array}$ & $56.67 \%$ & $66.67 \%$ & $83.33 \%$ \\
\hline 2 & $\begin{array}{l}\text { Siswa menjelaskan fungsi alat dan bahan } \\
\text { yang digunakan }\end{array}$ & $30 \%$ & $43.33 \%$ & $70 \%$ \\
\hline 3 & $\begin{array}{l}\text { Siswa mengklasifikasikan bahan yang aman } \\
\text { digunakan tanpa alat bantu dan bahan yang } \\
\text { perlu alat bantu }\end{array}$ & $40 \%$ & $56.67 \%$ & $76.67 \%$ \\
\hline 4 & $\begin{array}{l}\text { Siswa menimbang bahan dan mengukur } \\
\text { berapa banyak air yang akan digunakan } \\
\text { dalam membuat produk }\end{array}$ & $90 \%$ & $93.33 \%$ & $96.67 \%$ \\
\hline 5 & $\begin{array}{l}\text { Siswa menjelaskan penggunaan alat dan } \\
\text { bahan pada proses pembuatan produk }\end{array}$ & $63.33 \%$ & $76.67 \%$ & $83.33 \%$ \\
\hline 6 & $\begin{array}{l}\text { Siswa mendeskripsikan secara umum } \\
\text { prosedur pelaksanaan pembuatan produk }\end{array}$ & $36.67 \%$ & $56.67 \%$ & $80 \%$ \\
\hline 7 & $\begin{array}{l}\text { Siswa menjelaskan tahap-tahap pembuatan } \\
\text { produk }\end{array}$ & $33.33 \%$ & $50 \%$ & $66.67 \%$ \\
\hline 8 & $\begin{array}{lll}\text { Siswa mengungkapkan manfaat } & \text { dan } \\
\text { kelebihan produk } & & \\
\end{array}$ & $50 \%$ & $46.67 \%$ & $50 \%$ \\
\hline 9 & $\begin{array}{l}\text { Siswa menghitung peluang usaha pembuatan } \\
\text { produk }\end{array}$ & $66.67 \%$ & $70 \%$ & $63.33 \%$ \\
\hline 10 & $\begin{array}{l}\text { Siswa bertanya ketika fasilitator menjelaskan } \\
\text { teori dan demonstrasi pembuatan produk }\end{array}$ & $60 \%$ & $33.33 \%$ & $16.67 \%$ \\
\hline & Rata-rata & $52.67 \%$ & $59.33 \%$ & $68.67 \%$ \\
\hline
\end{tabular}

Dari nilai rata-rata dapat dilihat bahwa secara umum pemahaman materi pelatihan siswa semakin meningkat dari pelatihan 1 sampai pelatihan 3 . Berdasarkan pengamatan penulis, hal tersebut terjadi karena materi pada pelatihan 1 yaitu pembuatan produk sabun mandi cair memiliki tingkat kesulitan yang tinggi dibandingkan pelatihan 2 dan 3 . Tingkat kesulitan pembuatan produk sabun mandi cair dibandingkan produk sabun lainnya terletak pada dua hal yaitu (1) jenis bahan 
kimia yang digunakan lebih beragam, dan (2) tahapan pembuatan produk lebih banyak.

Tabel 2. Persentase Hasil Angket Pemahaman Pembuatan Produk Melalui Pelatihan

\begin{tabular}{|c|c|c|c|c|}
\hline \multirow{2}{*}{ No } & \multirow{2}{*}{ Pertanyaan } & \multicolumn{3}{|c|}{ Persentase } \\
\hline & & Pelatihan 1 & Pelatihan 2 & Pelatihan 3 \\
\hline 1 & $\begin{array}{l}\text { Pengenalan alat dan bahan melalui pelatihan } \\
\text { membuat saya mengetahui dan memahami } \\
\text { fungsi dan kegunaan masing-masing }\end{array}$ & $100 \%$ & $100 \%$ & $100 \%$ \\
\hline 2 & $\begin{array}{l}\text { Melalui kegiatan pelatihan saya dapat } \\
\text { mengenal bahan-bahan pembuatan produk } \\
\text { dengan berbagai kualitas }\end{array}$ & $93.33 \%$ & $96.67 \%$ & $96.67 \%$ \\
\hline 3 & $\begin{array}{l}\text { Saya dapat membuat produk dengan bahan } \\
\text { yang sesuai budget }\end{array}$ & $83.33 \%$ & $90 \%$ & $93.33 \%$ \\
\hline 4 & $\begin{array}{l}\text { Pembuatan produk melalui pelatihan } \\
\text { membuat saya lebih memahami tahapan- } \\
\text { tahapan yang harus dilakukan }\end{array}$ & $100 \%$ & $96.67 \%$ & $100 \%$ \\
\hline 5 & $\begin{array}{l}\text { Melalui pelatihan saya mengetahui peluang } \\
\text { usaha dan manajemen pemasaran produk }\end{array}$ & $90 \%$ & $93.33 \%$ & $96.67 \%$ \\
\hline 6 & $\begin{array}{l}\text { Dengan kegiatan pelatihan pembuatan } \\
\text { produk saya dapat menentukan segmen pasar } \\
\text { sebagai peluang usaha }\end{array}$ & $86.67 \%$ & $86.67 \%$ & $93.33 \%$ \\
\hline 7 & $\begin{array}{l}\text { Melalui pelatihan saya dapat membuat } \\
\text { produk yang murah namun berkualitas setara } \\
\text { dengan produk di pasaran }\end{array}$ & $83.33 \%$ & $93.33 \%$ & $96.67 \%$ \\
\hline 8 & $\begin{array}{l}\text { Dengan mengetahui } \quad \text { tahapan-tahapan } \\
\text { pembuatan produk, saya dapat } \\
\text { menerapkannya sendiri dan membuat produk } \\
\text { rumahan }\end{array}$ & $83.33 \%$ & $90 \%$ & $96.67 \%$ \\
\hline 9 & $\begin{array}{l}\text { Belajar membuat produk dengan praktik } \\
\text { langsung lebih menarik minat }\end{array}$ & $100 \%$ & $100 \%$ & $100 \%$ \\
\hline 10 & $\begin{array}{l}\text { Pembuatan produk skala rumahan perlu } \\
\text { diselenggarakan di sekolah untuk menambah } \\
\text { pengetahuan, wawasan, dan minat siswa }\end{array}$ & $100 \%$ & $100 \%$ & $100 \%$ \\
\hline & Rata-rata & $91.99 \%$ & $94.67 \%$ & $97.33 \%$ \\
\hline
\end{tabular}

Tabel 2 menggambarkan persentase hasil pemahaman pembuatan produk Saponify Handmade Soap melalui pelatihan. Berdasarkan data pada tabel di atas menunjukkan bahwa rata-rata pemahaman pembuatan produk pada pelatihan 1 sampai pelatihan 3 mengalami peningkatan. Pembuatan produk pada pelatihan 3 yaitu sabun pembersih lantai mendapat persentase hasil pemahaman siswa paling tinggi yaitu sebesar $97.33 \%$. Hal itu terjadi karena pembuatan produk sabun pembersih lantai pada prosesnya menggunakan alat dan bahan yang minim serta 
tahapan pembuatan yang lebih singkat dibandingkan dua sabun lainnya. Secara keseluruhan siswa memberikan respon yang positif dalam kegiatan pelatihan pembuatan Saponify Handamde Soap ini.

\section{SIMPULAN SARAN}

Simpulan dari kegiatan pengabdian pada masyakarat yang berupa pelatihan pembuatan Saponify Handmade Soap ini diantaranya, yaitu:

a. Terasahnya kemampuan siswa di luar keahlian yang diajarkan di sekolah yaitu dalam bidang Saponify Handmade Soap, trik dan tips dalam produksi, dan teknik marketing produk.

b. Bertambahnya pengetahuan dan pengalaman siswa SMKN dalam memproduksi bahan kebersihan rumah tangga dalam hal ini Saponify Handmade Soap.

c. Kemampuan siswa SMK dalam membuat atau menghasilkan Saponify Handmade Soap dan keilmuan dalam membuka lapangan usaha/ kerja baru bidang Saponify Handmade Soap sehingga dapat menjadi alternatif mencari nafkah/ penghidupan

Adapun saran dari rangkaian kegiatan pengabdian ini dalam rangka menurunkan angka persentase pengangguran lulusan SMK dan mencegah lulusan tidak bekerja, diantaranya yaitu:

a. Pentingnya mengembangkan keahlian lain di luar keahlian yang sudah ada di sekolah, khususnya livelihood skills dan entrepreneur skills melalui pelatihan Saponify Handamade Soap untuk tambahan wawasan lain dan dapat digunakan sebagai alternatif mencari penghidupan.

b. Semakin beragamnya informasi mengenai keahlian-keahlian lain yang menunjang dalam mewujudkan lulusan produktif dan dapat membuka 
lapangan usaha/ kerja di luar keahlian yang diajarkan di sekolah, menuntut pihak sekolah mengadakan pelatihan di luar keahlian yang sudah ada di sekolah sebagai pembekalan bagi lulusannya.

\section{UCAPAN TERIMAKASIH}

Penulis mengucapkan terimakasih dan penghargaan kepada Kemenristek Dikti yang telah membiayai kegiatan pengabdian skim Ipteks bagi Masyarakat (IbM) tahun anggaran 2015 ini.

\section{DAFTAR PUSTAKA}

[1] Departemen Pendidikan Nasional Republik Indonesia. 2006. Undang-undang Republik Indonesia Nomor 20 Tahun 2003 tentang Sistem Pendidikan Nasional. Depdiknas. Jakarta.

[2] Pendidikan Menengah Kejuruan. 2008. Kurikulum SMK. Dikmenjur. Jakarta.

[3], [8], [10] Direktorat Jenderal Pendidikan Menengah (Renstra Ditjen Dikmen). 2012. Renstra Ditjen Dikmen 2010-2014. Kementerian Pendidikan dan Kebudayaan. Jakarta.

[4], [5] Kajian Ekonomi Regional Provinsi Banten. 2013. Kajian Ekonomi Regional Provinsi Banten Triwulan III-2013. Bank Indonesia Provinsi Banten. Serang.

[7] Soussan, P., Blaikie, S. B., \& Chadwik. 2011. Understanding Livelihood Processes and Dynamics. DFID. United Kingdom.

[9] ILO Indonesia. 2013. Tren Ketenagakerjaan dan Sosial di Indonesia 2013. ILO. Jakarta.

[11] International Recovery Platform. 2012. Guidance Note on Recovery Livelihood. IRP. Japan.

[12] EQUIP3. 2005. Youth Livelihood Toolkit: Preparing Out-of-School Youth for Livelihood. EQUIP3. United States.

[13] LPPM Unsera. 2013. Rencana Induk Penelitian Universitas Serang Raya 2013-2016. Unsera. Serang. 